\title{
Disaster Preparedness and Response for the \\ Burn Mass Casualty Incident in the Twenty-first Century
}

\author{
Randy D. Kearns, DHA, MSA, CEM ${ }^{a}, *$, \\ David E. Marcozzi, MD, MHS-CL ${ }^{b, c}$, Noran Barry, MD ${ }^{d}$, \\ Lewis Rubinson, MD, PhD ${ }^{\mathrm{e}}$, \\ Charles Scott Hultman, MD, MBA ${ }^{f}$, \\ Preston B. Rich, MD, MBA ${ }^{9}$
}

\section{KEYWORDS}

- Burn injury • Mass casualty incident • Disaster preparedness • Surge capacity

\section{KEY POINTS}

- Managing the Burn Mass Casualty Incident requires planning and a unique knowledge of where the resources are located.

- More resources are available (trauma services) when the disaster includes only burn injured patients (nightclub fire versus industrial plant explosion).

- If the disaster includes infrastructure damage such as an earthquake or a terrorist explosion, it may hinder patients coming to you or being able to transfer them to other facilities.

- The first line of defense is what you have at your facility to include what you can create by adapted spaces and reverse triage in the hospital with the aim of discharging those who can go home.

- Housekeeping staff play a vital role getting rooms cleaned if rapid discharge decisions need to be made to create more space. Involve them in the planning process.

\section{INTRODUCTION}

Due to their unpredictability and indiscriminate impact on either unprepared and seemingly riskfree populations or military populations, disasters of even local magnitude tend to be large-scale media events, and the associated responses to them are subject to intense media scrutiny. As a result, society's exposure to mass casualty incidents (MCls) and their associated management are commonly measured through a sensational and incomplete lens of media outlets. This skewed, remote, and occasionally distanced perspective can often lead to harsh unproductive critiques of observed actions viewed out of context, focused praise of certain isolated high-profile efforts, or harsh judgment of perceived failures with little science to judge operations, outcomes, or perspectives offered.

In contrast, the perspective of health care responders who become engulfed in the actual

\footnotetext{
a Management Services Division, Tillman School of Business, University of Mount Olive, Mount Olive, NC, USA;

b The University of Maryland School of Medicine, 620 West Lexington Street, Baltimore, MD 21201, USA;

c USAR, US Army Special Operations Command, Ft. Bragg, NC, USA; d Acute Care Surgery, Department of Sur-

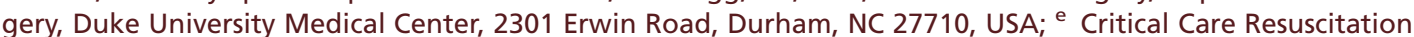
Unit, R. Adams Cowley Shock Trauma Center, University of Maryland School of Medicine, Baltimore, MD, USA;

${ }^{f}$ Department of Surgery, University of North Carolina School of Medicine, Chapel Hill, NC, USA; ${ }^{g}$ Acute Care Surgery, Department of Surgery, University of North Carolina School of Medicine, Chapel Hill, NC, USA

* Corresponding author.

E-mail address: randy.kearns@earthlink.net
} 
chaos of an unfolding disaster is real, dynamic, complicated, and inherently linked to emotion. The scope and scale of a given disaster, the quantity or quality of available resources, or the geopolitical implications of a particular event can vary widely. Each disaster response can be universally reduced to the aggregate actions of individuals who are called on to make complex, immediate, and high-stake decisions that ultimately contribute to the outcome. Although the process always begins with first responders, it systematically evolves and expands throughout the entire health care system, inclusive of 9-1-1 call systems, emergency medical systems (EMS), triage centers, initial receiving hospitals, and definitive care and postacute facilities, extending well into available rehabilitation and psychosocial support infrastructure. Disasters are fundamentally local community events that commonly grow to involve regions, nations, and sometimes even manifest global impact.

Disasters are local events. Therefore, sound community $\mathrm{MCl}$ planning is critical to effecting excellent patient outcomes. Capacity and capability are inherently resource-based. This requires the development and implementation of thoughtful, carefully crafted, and individually designed emergency plans that match potential needs with a progressive echelon of available or potentially available response assets. ${ }^{1}$

Although first-responder personnel commonly consist of local EMS, fire, hazardous materials (HAZMAT), or rescue assets, training and available equipment often vary significantly between jurisdictions. Furthermore, the initial facilities that receive the first wave of patients may range from major regional referral medical centers to minimally staffed critical access hospitals and may even consist of temporary mobile shelters.

Given these known and anticipated variabilities in available resources, pre-incident planning is crucial. This planning contributes to the provision of consistent care delivered through the rational coordination of integrated system-level care networks. ${ }^{2-4}$ When disaster strikes, the first calls for help are funneled to the local 9-1-1 center (although $9-1-1$ is the number used primarily in the United States and other countries, this number varies in other countries to include 9-9-9 and 1-1-2 being several of the more common).

Once the call is placed to the emergency communications center, the trigger point for all disasters with a medical component will rest on the shoulders of the local EMS system. Thus, the first wave of patients will be managed by EMS personnel (the First Responders) and the emergency department physicians and nurses (the First
Receivers). It should be noted that casualty evacuation may take on many forms, including the use of privately owned and law enforcement vehicles. Nevertheless, a vast majority of patients are initially managed by first responders and all those with serious injuries are managed by the first receivers.

\section{TYPES OF MEDICAL DISASTERS}

Burn injuries are one of the most challenging medical disaster scenarios. Burn $\mathrm{MCl}(\mathrm{BMCl})$ typically can be linked to 1 of 3 broad scenarios: a mass gathering, such as a theater, dinner, or nightclub with a sudden fire; natural disaster, such as wildfire or earthquake; or purposeful hostilities, such as terrorism, bomb blast, or an act of war. ${ }^{5}$ As an event becomes more complex, the variety of wounds and concomitant injuries will require a more diverse response. If there is concurrent damage to infrastructure that limits hospital care or limits transportation access, the problems and limitations may grow exponentially.

Despite the infrequent nature of medical disasters, their initial management and the subsequent surge in capacity that necessarily follows, quickly becomes the greatest challenge, and potential threat to a given hospital, health care system, or region. ${ }^{3,6}$ Learning from these events, whether civilian or military, offers opportunities for improvement in approach to trauma delivery across the nation and around the world. ${ }^{7}$ The purpose of this article was to review the basics of disaster planning, preparedness, response, and recovery in the aftermath of a medical disaster. Although the primary focus is $\mathrm{BMCl}$, illustrative examples include natural disaster and infectious disease principles.

\section{CONTENT: WHY BURN INJURIES?}

Patients with significant burn injuries represent a small subset of patients; however, due to their complexity and injury severity, they impose a disproportionate impact on health care systems. A recent survey revealed that even seasoned practitioners, including experienced physicians, nurses, and paramedics, stated they were "uncomfortable with their knowledge, skills, and ability to care for a burn-injured patient." 8

The capability to effectively manage and care for $\mathrm{BMCl}$ is a critical determinant of desirable outcomes in the care of patients with burn injuries. ${ }^{9-12}$ Given the scarcity of resources and the infrequency of $\mathrm{BMCl}$ events, it is reasonable to consider and plan for these events as worst-case scenarios in modern health care systems. 
Successful BMCl planning includes thorough examination of existing internal protocols, patient flow parameters, and the engagement of all pertinent stakeholders. ${ }^{5,13}$ Geography and lines of political jurisdiction are important planning factors, and close coordination and communication between various burn centers are essential for a successful response. ${ }^{14,15}$

\section{ALL-HAZARDS, CAPABILITY-BASED PLANNING, SURGE CAPACITY, AND THE STANDARD OF CARE}

The critical phase of $\mathrm{MCl}$ planning involves initial patient assessment and management, individualized triage, and subsequent referral to accepting definitive care centers. Preparations for largescale events must include plans to address surge resources on local, regional, and national scales. ${ }^{1,4,16-18}$ Capacity refers to the quantity of staff, space, and supplies (pharmaceuticals and equipment) available. Capability refers to the types of clinicians available to render appropriate care for the sick and injured, as well as the quality of equipment needed to perform certain procedures.

Key factors that determine capacity include commonly available routinely used resources in addition to key assets that can be flexed to specifically accommodate $\mathrm{MCl}$ needs, such as holding areas, outpatient facilities, conference rooms, and often the adaptation of temporary structures to serve this purpose.$^{19,20}$ An important measure of scalable capacity is the ability to increase bed availability through flexing by $20 \%$ within 4 hours for the highest acuity patients. ${ }^{19}$

Factors to consider in a capability analysis include available equipment and its asset typing, noninventory materials that have the potential for shipping and receiving, and available personnel with detailed credentialing information. ${ }^{4}$ In addition, an understanding of transportation assets, multijurisdictional, and multiagency are imperative. ${ }^{21}$

\section{FACILITY PLANNING}

Over the past 10 years, clinicians have gained a greater understanding in the assessment and management of $\mathrm{MCls}$ with regard to the fine balance of staff, space, and supplies. ${ }^{22,23}$ By 2009, the surge planning had evolved to stratify surge capacity into 3 defined categories: Conventional, Contingency, and Crisis Surge Capacities. ${ }^{18,21}$

Some mass casualty events can be managed with limited strain on existing health care resources. At times, surging requires only small modifications in staffing, hospital-based equipment, and treatment facility spaces. In these cases, traditional standards of care may remain intact.

In events where needs outstrip resources, traditional standards of care and expectations require modification. Contingency surge capacity measures may include such things as provision of medical care in otherwise nontraditional settings and/or by nontraditional practitioners. Staffing will still often include clinicians with traditional credentials but who may be unaccustomed with the specialized care that will need to be delivered. Supplies are commonly limited in these settings, and in some cases substitute medications or fluids may need to be used. The most unpredictable limitation is the availability of and access to supplies and specialty equipment, such as intravenous pumps and ventilators.

Crisis Surge Capacity implies that the practices of care may, by necessity, extend outside of what may be considered traditional standards of care. Although often required under these conditions, mitigation strategies should be enacted to alleviate them as soon as is reasonably possible. The pre-incident planning process provides an ideal opportunity to engage informed policymakers to define community care standards under various potential disaster scenarios, provide guidelines for acceptable care under resourceconstrained conditions, and outline reasonable expectations for the infrastructure needed to manage any given disaster event.

\section{SURGE EQUILIBRIUM}

As a disaster scenario unfolds, there are trigger points that often mark event stabilization. The achievement of this state of relative balance (known as surge equilibrium, represented in Fig. 1) can be identified when sufficient numbers of patients have been transferred, discharged, or died. This inflection point creates conditions whereby patients with ongoing needs can be met on a steady and predictable basis by the staff, space, and supplies available for use. Effective and efficient transportation resources are often effective tools to enable relative patient decompression during a disaster by allowing rational triage of acutely injured or ill patients to appropriate receiving facilities and simultaneously shuttling supplies, personnel, and temporary treatment facilities to the disaster site.

\section{IMMEDIATE BED AVAILABILITY, ALTERNATIVE STAFF RESOURCES, JUST-IN-TIME TRAINING, AND FORCE MULTIPLIERS}

A core strategy for disaster process planning is implementation of an immediate bed availability 


\section{SURGE EQUILIBRIUM}

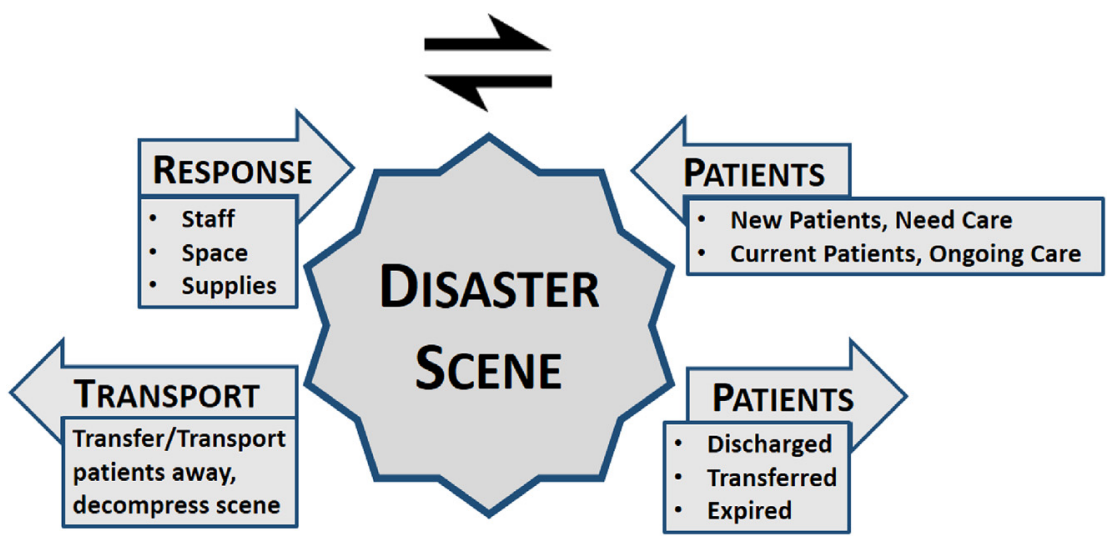

Fig. 1. The target is to reach surge equilibrium and provide care based on traditional standards of care. The 3 time phases may vary slightly based on quantity of available resources and proximity to the site of the $\mathrm{BMCl}$ (or burn disaster). Thus, as ranges in other state and regional plans are reviewed, they may not have the same precise 3 blocks of time. Nevertheless, the 3 general periods, immediate, intermediate (loosely defined as 6120 hours), and extended (the 120 hours post disaster), are general windows for what is identified as a type III burn disaster. These windows of time may grow when the $\mathrm{BMCl}$ is competing for resources, such as with an explosion (type II), or there is impact to the infrastructure, such as an earthquake that damages the hospital or limits highway access for patient transport (type I). Surge Equilibrium: all competing influences of the disaster are balanced at the point of where the patients are being managed, disaster scene or at the hospital.

(IBA) approach, which emphasizes the deliberate triage and discharge of affected patients to available medical resources with reliance on existing personnel to receive and treat the initial influx of patients from an $\mathrm{MCl}$. Ideally, IBA tactics should be expected to generate $20 \%$ more resources with no more than 4 hours' notice.

Strategies to surge staff include force multipliers through just-in-time (JIT) training by using personnel who have the aptitude to quickly learn, adapt, and assist. ${ }^{24}$ Cross-training before a disaster can effectively augment personnel pools in preparation for an $\mathrm{MCl}$ event, but for logistic reasons may not be a viable option for smaller organizations. Military surge strategies offer excellent examples of how to systematically leverage medical resources by flexing available manpower that may not be considered traditional clinical complements. JIT training paradigms can augment targeted capabilities over relatively short time frames and can provide large groups of caregivers led by specially trained medical team leaders, allowing systems to manage large numbers of acute care patients. ${ }^{25,26}$ Telemedicine platforms may also be used to augment staff and provide expert assistance "virtually" when the necessary technology is available to support the effort. ${ }^{27}$

Effective strategies that are commonly used to expand staffing resources during a crisis surge is the planned incorporation of disaster medical responders from other communities via preexisting memoranda of understanding or capability expansion through the JIT training and use of nontraditional personnel. Availability of these resources varies widely between jurisdictions, and often includes state or regional teams in addition to federal disaster resources. The federal disaster teams are incorporated into the National Disaster Medical System (NDMS) within the US Department of Health and Human Services. This multifaceted approach facilitates the coordinated surge response, including both specialized equipment and personnel directly into the affected area and provides integrated transportation resources allowing patient movement away from the disaster site. ${ }^{28}$

Historically, the BMCI has also been widely discussed as a burn disaster. ${ }^{5}$ For the purpose of using a common language, 3 general $\mathrm{BMCl}$ scenarios were identified, relying on National Incident Management System standards, ${ }^{29}$ to aid disaster planners with a common language (detailed in Box 1). The 3 scenarios established 3 broad groups that escalate in complexity: one that impacts the burn care system, one that impacts the broader health care system, and one that reflects an impact on critical infrastructure.

The inherent complexity of disasters that include both trauma and burn-injured patients creates a scenario of competition for resources placing enormous pressure on the health care system to meet all of the needs within a traditional standard of care. ${ }^{5}$ However, when infrastructure is catastrophically 
Box 1

These are the 3 basic types of burn mass casualty incidents relying on the National Incident Management System order of classification; these classifications were first published in 2014

\section{Burn Mass Casualty Incident (BMCI) (Burn Disaster) Scenarios}

Type I BMCI:

- Description and example: catastrophic event, to include multiple casualties with various and combined burn injuries over a wide geographic area, such as earthquakes to include the 1994 Northridge earthquake, ${ }^{68,69}$ the $9 / 11$ attacks, $^{70-72}$ the Great East Japan earthquake (2011), ${ }^{51,73}$ or an improvised nuclear device. ${ }^{57,60,74,75}$

- Impact: critical infrastructure

- Logic: impact to the infrastructure could be devastating. When the infrastructure is damaged, from highways to utilities, the magnitude of the disaster is amplified by the compromised facilities. When the facilities in which care is provided are damaged or essential utilities are disrupted, in addition to the surge of both burn and general traumatic injuries, most likely the management of the disaster will be suboptimal. Radiation-related incidents would include activation of the Radiation Injury Treatment Network, a cooperative effort of the National Marrow Donor Program and the American Society for Blood and Marrow Transplantation. ${ }^{76}$

Type II BMCl:

- Description and example: multiple-aspect burn disaster, such as an explosion, with significant numbers of traumatic as well as burn-injured patients producing multiple casualties with various blunt force and combined thermal injuries. This type of disaster would include the Madrid train bombings (2004) $)^{65,66}$ and London subway attack (2005). ${ }^{67}$

- Impact: health care system

- Logic: impact to the health care system may be significant; due to the nature of the disaster, there may or may not be ample critical care and trauma care beds that can be adapted to care for those burninjured patients who need less intensive attention by burn care professionals. Given the competing interests of traumatic injury with burn injury, filling the need without crossing into a crisis surge capacity may be problematic in the immediate geographic area near the site of the disaster.

Type III BMCl:

- Description and example: an isolated burn disaster with mostly thermal injuries, such the Rhode Island Station Night Club fire (2003) $)^{61-63}$ or the Kiss Nightclub fire in Santa Maria, Brazil (2013). ${ }^{64}$

- Impact: burn care system

- Logic: impact to the burn care system may be significant; but due to the nature of the disaster, critical care and trauma care beds can be adapted to provide care for burn-injured patients who need less intensive attention by burn care professionals.

damaged or destroyed (eg, earthquakes), the result will most likely include widespread care being provided outside the typical standards. The downstream effect includes extending the stress into a region well beyond the impacted area. As such, earthquakes or any disaster that creates widespread damage to the infrastructure continues to be a focus for disaster planning. ${ }^{5}$

\section{THREE STAGES OF ACTIVITY DURING A DISASTER PLAN Activation Point/Trigger(s)}

Disaster plans must include an activation point (trigger). Triggers are identified by a combination of data or science and the opinions of the subject matter experts. All disaster plans should offer sufficient latitude to move into the context of the plan early on in the disaster, in an attempt to control the common tendency toward chaos.

\section{Functional Period of Activity}

Disaster plans must have a functional period of activity. This functional activity can be tested and assessed through simulation and actual use. Simulation provides an opportunity to simultaneously test numerous inputs and variables in a cost-effective laboratory setting to identify potential plan weaknesses and augment plan strengths.

Three commonly used modeling techniques include Monte Carlo Simulation, Discrete Event Simulation, and Continuous Simulation. Modeling 
is routinely performed in an academic environment and numerous published surge models exist based on these systems. ${ }^{30-38}$

Methods to test planning efforts can include (virtual) table-top exercises, functional scenarios (in which 1 or more specific components are tested), and full-scale simulation involving the physical participation of many personnel and structures. ${ }^{39}$ In the aftermath of any disaster, it is essential to develop an after-action report (AAR) to identify successes and opportunities for improvement in which existing plans can be modified or improved based on actual experiences. Incorporating Lean and Six Sigma tools, such as spaghetti plots and process maps, can significantly enhance the quality of AARs.

\section{Plan Failure}

No disaster plan is infinitely scalable. In fact, when plans attempt to capture both the focus and the obscurity of disaster needs, inevitably disaster planning can become less focused and therefore potentially less effective. This can result in a plan that may, under certain conditions, fail to provide the appropriate guidance needed in a given event. In contrast, developing flexible plans that contain key components can serve as an operational framework providing responders with critical guidance in the event of loss of containment.

Any plan must also consider where additional resources can be accessed and facilitate efficient and effective coordination with other hospitals or burn centers within an immediate area (referred to as interfaculty planning). Based on geography and proximity, the closest resources may be located in an adjacent community or across a state line. The immediate resources, along with contact information, should be reflected in the plan.

\section{WORST-CASE SCENARIOS}

Aside from the $\mathrm{BMCl}$, pandemic events have produced several of the greatest threats faced by health care systems over the past 100 years. Recently there have been several large-scale global events, such as the $2009 \mathrm{H} 1 \mathrm{~N} 1$ influenza outbreak, ${ }^{40}$ that reached pandemic proportions based on patient numbers and viral characteristics but not in terms of patient mortality. On the other hand, several outbreaks, including Severe Acute Respiratory Syndrome Coronavirus ${ }^{41,42}$ and the Ebola Virus Disease, ${ }^{43-46}$ manifested higher mortality rates but never reached pandemic proportions as defined by World Health Organization.
Although infrequent, radiation-related disasters represent novel and challenging threats that can put health care systems at great risk. The use of radiation equipment is common in hospitals. As such, there is ready access to detection equipment as well. Experience shows that large radionuclear events, such as occurred in Chernobyl, Russia (1986), ${ }^{47,48}$ and Fukushima, Japan (2011), ${ }^{49-51}$ can have devastating and long-term local, regional, national, and global impact.

Nuclear weapons, such as those used in Hiroshima and Nagasaki, Japan, killed more than 100,000 and left an equal number of people with acute radiation illnesses. ${ }^{52-54}$ Modern technology allows for highly enriched weapons, with a similar yield to the Hiroshima weapon, that could be concealed in a small container the size of suitcase. The potential use of highly enriched weaponized fissile materials represents the ultimate terrorism threat. If used, this would rapidly overwhelm all traditional resources for an extended period, even in developed countries such as the United States. ${ }^{55-60}$

\section{SUMMARY}

The $\mathrm{BMCl}$ scenario represents a very challenging and clinically significant event. Successful preincident planning can help facilitate the coordinated care of the these severely injured patients. Flexibility in planning must account for initial patient management, the surging of available resources, and the coordinated regional dispersion of patients to definitive care facilities. Plans can be effectively tested through well-recognized simulation techniques, which can help identify opportunities for improvement, and augment existing strengths. The AAR process is an ideal opportunity to reinforce effective practices, and fill in gaps previously unanticipated. During an $\mathrm{MCl}$, speed, repetition, simplicity, and creativity are critical components of success.

\section{REFERENCES}

1. Healthcare Preparedness Capabilities, National Guidance for Healthcare System Preparedness. In: Response OotASfPa, ed. US DHHS ASPR. 2012. Available at: http://www.phe.gov/Preparedness/ planning/hpp/reports/Documents/capabilities.pdf. p. 72. Accessed April 1, 2017

2. VandenBerg SL, Davidson SB. Preparation for mass casualty incidents. Crit Care Nurs Clin North Am 2015;27(2):157-66.

3. Hick JL, Hanfling D, Cantrill SV. Allocating scarce resources in disasters: emergency department principles. Ann Emerg Med 2012;59(3):177-87. 
4. Kearns RD, Cairns BA, Cairns CB. Surge capacity and capability. A review of the history and where the science is today regarding surge capacity during a mass casualty disaster. Front Public Health 2014;2:29.

5. Kearns RD, Conlon KM, Valenta AL, et al. Disaster planning: the basics of creating a burn mass casualty disaster plan for a burn center. J Burn Care Res 2014;35(1):e1-13.

6. Hick JL, Einav S, Hanfling D, et al. Surge capacity principles: care of the critically ill and injured during pandemics and disasters: CHEST consensus statement. Chest 2014;146(4 Suppl):e1S-16S.

7. National Academies of Sciences E, Medicine. A National Trauma Care System: integrating military and civilian trauma systems to achieve zero preventable deaths after injury. Washington, DC: The National Academies Press; 2016.

8. Kearns RD, Ortiz-Pujols SM, Craig CK, et al. Advanced burn life support for day-to-day burn injury management and disaster preparedness: stakeholder experiences and student perceptions following 56 advanced burn life support courses. J Burn Care Res 2015;36(4):455-64.

9. Barillo DJ. Planning for burn mass casualty incidents. J Trauma 2007;62(6 Suppl):S68.

10. Barillo DJ, Wolf S. Planning for burn disasters: lessons learned from one hundred years of history. J Burn Care Res 2006;27(5):622-34.

11. Conlon KM, Ruhren C, Johansen S, et al. Developing and implementing a plan for large-scale burn disaster response in New Jersey. J Burn Care Res 2014;35(1):e14-20.

12. Conlon KM, Martin S. 'Just send them all to a burn centre': managing burn resources in a mass casualty incident. J Bus Contin Emer Plan 2011;5(2):150-60.

13. Wachtel TL, Cowan ML, Reardon JD. Developing a regional and national burn disaster response. J Burn Care Rehabil 1989;10(6):561-7.

14. Kearns RD, Cairns BA, Hickerson WL, et al. ABA Southern Region Burn disaster plan: the process of creating and experience with the ABA southern region burn disaster plan. J Burn Care Res 2014; 35(1):e43-8.

15. Kearns R, Holmes JT, Cairns B. Burn disaster preparedness and the southern region of the United States. South Med J 2013;106(1):69-73.

16. Hick JL, DeVries AS, Fink-Kocken P, et al. Allocating resources during a crisis: you can't always get what you want. Minn Med 2012;95(4):46-50.

17. Hanfling D, Hick JL, Cantrill SV. Understanding the role for crisis standards of care. Ann Emerg Med 2012;60(5):669-70 [author reply: 670-1].

18. Hick JL, Barbera JA, Kelen GD. Refining surge capacity: conventional, contingency, and crisis capacity. Disaster Med Public Health Prep 2009;3(2 Suppl):S59-67.
19. Emergency PH. Immediate bed availability. 2014. Available at: http://www.phe.gov/Preparedness/ planning/sharper/Pages/iba.aspx. Accessed July, 7 2016.

20. Kearns RD, Skarote MB, Peterson J, et al. Deployable, portable, and temporary hospitals; one state's experiences through the years. Am J Disaster Med 2014;9(3):195-210.

21. Kearns RD, Hubble MW, Holmes JH, et al. Disaster planning: transportation resources and considerations for managing a burn disaster. J Burn Care Res 2014;35(1):e21-32.

22. Gerberding JL, Falk H, Arias I, et al. In a moment's notice: surge capacity for terrorist bombings challenges and proposed solutions. US Department of Health and Human Services, Centers for Disease Control. Available at: https://emergency.cdc.gov/ masscasualties/pdf/surgecapacity.pdf. Accessed April 7, 2017.

23. Kelen GD, McCarthy ML. The science of surge. Acad Emerg Med 2006;13(11):1089-94.

24. Posner Z, Admi H, Menashe N. Ten-fold expansion of a burn unit in mass casualty: how to recruit the nursing staff. Disaster Manag Response 2003;1(4): 100-4.

25. Lennarson P, Boedeker BH, Kuper GM, et al. Utilization of a civilian academic center as a force multiplier in support of NATO special operations medicine - a pilot demonstration. Stud Health Technol Inform 2012;173:260-2.

26. Bryan J, Miyamoto D, Holman V. Medical civilmilitary operations: the deployed medical brigade's role in counterinsurgency operations. US Army Med Department J 2008;25-8.

27. Simmons S, Alverson D, Poropatich R, et al. Applying telehealth in natural and anthropogenic disasters. Telemed J E health 2008;14(9):968-71.

28. Franco C, Toner E, Waldhorn R, et al. The national disaster medical system: past, present, and suggestions for the future. Biosecurity and bioterrorism: biodefense strategy, practice, and. science 2007; 5(4):319-25.

29. National Incident Management System. 2008. Available at: http://www.fema.gov/pdf/emergency/ nims/NIMS_core.pdf. Accessed December 7, 2012.

30. Abir M, Davis MM, Sankar P, et al. Design of a model to predict surge capacity bottlenecks for burn mass casualties at a large academic medical center. Prehosp Disaster Med 2013;28(1):23-32.

31. Albores P, Shaw D. Government preparedness: using simulation to prepare for a terrorist attack. Comput Oper Res 2008;35(6):1924-43.

32. Dallas CE, Bell WC. Prediction modeling to determine the adequacy of medical response to urban nuclear attack. Disaster Med Public Health Prep 2007;1(2):80-9. 
33. Franc-Law JM, Bullard M, Della Corte F. Simulation of a hospital disaster plan: a virtual, live exercise. Prehosp Disaster Med 2008;23(4):346-53.

34. Hirshberg A, Scott BG, Granchi T, et al. How does casualty load affect trauma care in urban bombing incidents? A quantitative analysis. J Trauma 2005; 58(4):686-95.

35. Smith SW, Portelli I, Narzisi G, et al. A novel approach to multihazard modeling and simulation. Disaster Med Public Health Prep 2009;3(2):75-87.

36. Steward D, Wan TT. The role of simulation and modeling in disaster management. J Med Syst 2007;31(2):125-30.

37. Kearns R, Zoller J, Hubble M, et al. Using Monte Carlo simulation for modeling surge capacity in the ABA southern region. J Burn Care Res 2012; 33(2): 1 .

38. Kearns RD. Burn surge capacity in the south: what is the capacity of burn centers within the American Burn Association southern region to absorb significant numbers of burn injured patients during a medical disaster? Medical University of South Carolina. [ProQuest Dissertations and Theses]. 2011.

39. Federal Emergency Management Agency. Homeland Security Exercise and Evaluation program. 2013; Available at: http://www.fema.gov/medialibrary-data/20130726-1914-25045-8890/hseep_ apr13_.pdf. Accessed July 6, 2016.

40. H1N WHOINfMMfPI. Studies needed to address public health challenges of the $2009 \mathrm{H} 1 \mathrm{~N} 1$ influenza pandemic: insights from modeling. PLoS Curr 2009; 1:RRN1135.

41. Cheng VC, Chan JF, To KK, et al. Clinical management and infection control of SARS: lessons learned. Antiviral Res 2013;100(2):407-19.

42. Xing W, Hejblum G, Leung GM, et al. Anatomy of the epidemiological literature on the 2003 SARS outbreaks in Hong Kong and Toronto: a time-stratified review. PLoS Med 2010;7(5):e1000272.

43. Kearns RD, Leaming LE. 'An abundance of caution' and Ebola in the US Healthcare System: what is the new normal? J Bus Contin Emer Plan 2015; 8(4):317-25.

44. McCarthy M. Liberian man being treated for Ebola in Texas dies. BMJ 2014;349:g6145.

45. McCarthy M. US issues new guidelines for health workers caring for Ebola patients. BMJ 2014;349: g6418.

46. Ki M. What do we really fear? The epidemiological characteristics of Ebola and our preparedness. Epidemiol Health 2014;36:e2014014.

47. Takada J. Chernobyl nuclear power plant accident and Tokaimura criticality accident. Nihon rinsho. Jpn J Clin Med 2012;70(3):405-9 [in Japanese].

48. Svendsen ER, Runkle JR, Dhara VR, et al. Epidemiologic methods lessons learned from environmental public health disasters: Chernobyl, the World Trade Center, Bhopal, and Graniteville, South Carolina. Int J Environ Res Public Health 2012;9(8):2894-909.

49. Sugimoto A, Krull S, Nomura S, et al. The voice of the most vulnerable: lessons from the nuclear crisis in Fukushima, Japan. Bull World Health Organ 2012; 90(8):629-30.

50. Robertson AG, Pengilley A. Fukushima nuclear incident: the challenges of risk communication. Asia Pac J Public Health 2012;24(4):689-96.

51. Fuse A, Yokota H. Lessons learned from the Japan earthquake and tsunami, 2011. J Nippon Med Sch 2012;79(4):312-5.

52. Matsunari $Y$, Yoshimoto $N$. Comparison of rescue and relief activities within 72 hours of the atomic bombings in Hiroshima and Nagasaki. Prehosp Disaster Med 2013;28(6):536-42.

53. Stalpers LJ, van Dullemen S, Franken NA. Medical and biological consequences of nuclear disasters. Ned Tijdschr Geneeskd 2012;156(20):A4394 [in Dutch].

54. Dallas CE. Medical lessons learned from Chernobyl relative to nuclear detonations and failed nuclear reactors. Disaster Med Public Health Prep 2012;6(4):330-4.

55. Knebel AR, Coleman CN, Cliffer KD, et al. Allocation of scarce resources after a nuclear detonation: setting the context. Disaster Med Public Health Prep 2011;5(Suppl 1):S20-31.

56. Hick JL, Weinstock DM, Coleman CN, et al. Health care system planning for and response to a nuclear detonation. Disaster Med Public Health Prep 2011; 5(Suppl 1):S73-88.

57. Goffman TE. Nuclear terrorism and the problem of burns. Am J Emerg Med 2011;29(2):224-8.

58. DiCarlo AL, Maher C, Hick JL, et al. Radiation injury after a nuclear detonation: medical consequences and the need for scarce resources allocation. Disaster Med Public Health Prep 2011;5(Suppl 1):S32-44.

59. Coleman CN, Weinstock DM, Casagrande R, et al. Triage and treatment tools for use in a scarce resources - crisis standards of care setting after a nuclear detonation. Disaster Med Public Health Prep 2011;5(Suppl 1):S111-21.

60. Coleman CN, Knebel AR, Hick JL, et al. Scarce resources for nuclear detonation: project overview and challenges. Disaster Med Public Health Prep 2011;5(Suppl 1):S13-9.

61. Gutman D, Biffl WL, Suner S, et al. The station nightclub fire and disaster preparedness in Rhode Island. Med Health R I 2003;86(11):344-6.

62. Harrington DT, BiffI WL, Cioffi WG. The station nightclub fire. J Burn Care Rehabil 2005;26(2):141-3.

63. Mahoney EJ, Harrington DT, Biffl WL, et al. Lessons learned from a nightclub fire: institutional disaster preparedness. J Trauma 2005;58(3):487-91.

64. Dal Ponte ST, Dornelles CF, Arquilla B, et al. Masscasualty response to the Kiss nightclub in Santa 
Maria, Brazil. Prehosp Disaster Med 2015;30(1): 93-6.

65. Gutierrez de Ceballos JP, Turegano Fuentes F, Perez Diaz D, et al. Casualties treated at the closest hospital in the Madrid, March 11, terrorist bombings. Crit Care Med 2005;33(1 Suppl):S107-12.

66. Turegano-Fuentes F, Caba-Doussoux P, JoverNavalon JM, et al. Injury patterns from major urban terrorist bombings in trains: the Madrid experience. World J Surg 2008;32(6):1168-75.

67. Chim H, Yew WS, Song C. Managing burn victims of suicide bombing attacks: outcomes, lessons learnt, and changes made from three attacks in Indonesia. Crit Care 2007;11(1):R15.

68. Shoaf KI, Sareen HR, Nguyen LH, et al. Injuries as a result of California earthquakes in the past decade. Disasters 1998;22(3):218-35.

69. Peek-Asa C, Kraus JF, Bourque LB, et al. Fatal and hospitalized injuries resulting from the 1994 Northridge earthquake. Int J Epidemiol 1998;27(3): 459-65.

70. Cushman JG, Pachter HL, Beaton HL. Two New York City hospitals' surgical response to the September 11, 2001, terrorist attack in New York City. J Trauma 2003;54(1):147-54 [discussion: 154-5].
71. Yurt RW, Bessey PQ, Bauer GJ, et al. A regional burn center's response to a disaster: September 11, 2001, and the days beyond. J Burn Care Rehabil 2005;26(2): 117-24.

72. Jordan MH, Hollowed KA, Turner DG, et al. The Pentagon attack of September 11, 2001: a burn center's experience. J Burn Care Rehabil 2005;26(2):109-16.

73. Koyama A, Fuse A, Hagiwara J, et al. Medical relief activities, medical resourcing, and inpatient evacuation conducted by Nippon medical school due to the Fukushima Daiichi nuclear power plant accident following the Great East Japan earthquake 2011. J Nippon Med Sch 2011;78(6):393-6.

74. Bargues L, Donat N, Jault $P$, et al. Burns care following a nuclear incident. Ann Burns Fire Disasters 2010;23(3):160-4 [in French].

75. Caro JJ, DeRenzo EG, Coleman CN, et al. Resource allocation after a nuclear detonation incident: unaltered standards of ethical decision making. Disaster Med Public Health Prep 2011;5(Suppl 1): S46-53.

76. Ross JR, Case C, Confer D, et al. Radiation injury treatment network (RITN): healthcare professionals preparing for a mass casualty radiological or nuclear incident. Int J Radiat Biol 2011;87(8):748-53. 